\title{
Intraductal Papillary Breast Carcinoma
}

National Cancer Institute

\section{Source}

National Cancer Institute. Intraductal Papillary Breast Carcinoma. NCI Thesaurus. Code C4190.

A non-invasive breast adenocarcinoma located in a distended duct. It is characterized by the presence of papillary structures with fibrovascular stalks. In the absence of ductal carcinoma in situ or invasive carcinoma in adjacent tissues, the prognosis is usually favorable. 